\title{
Erratum to: Uncovering ITIL claims: IT executives' perception on benefits and Business-IT alignment
}

\author{
Mauricio Marrone $\cdot$ Lutz M. Kolbe
}

Published online: 3 February 2011

(C) Springer-Verlag 2011

\section{Erratum to: Inf Syst E-Bus Manage DOI 10.1007/s10257-010-0131-7}

Unfortunately, the incorrect versions of Tables 4 and 6 were published. The correct versions of both Tables 4 and 6 are given below.

Table 4 Descriptive statistics of Business-IT alignment $(n=441)$

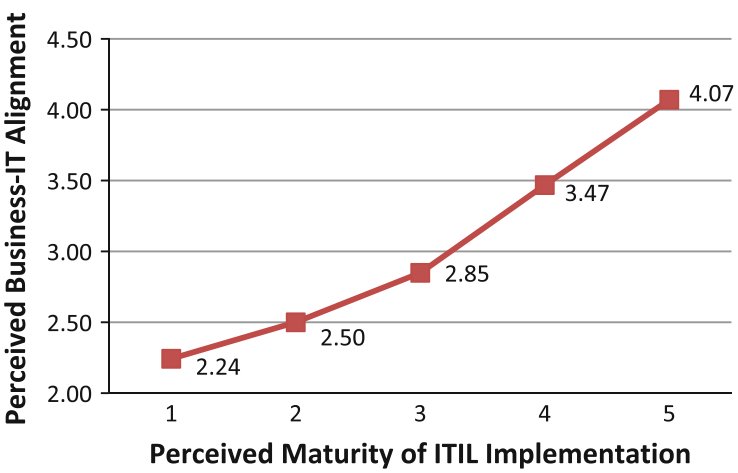

\begin{tabular}{|c|c|c|c|}
\hline $\begin{array}{c}\text { Maturity } \\
\text { Level }\end{array}$ & Mean & Median & $\mathrm{N}$ \\
\hline 1 & $\begin{array}{r}2.24 \\
S E=.25\end{array}$ & 2 & 33 \\
\hline 2 & $\begin{array}{r}2.50 \\
S E=.10\end{array}$ & 2 & 138 \\
\hline 3 & $\begin{array}{r}2.85 \\
S E=.12\end{array}$ & 3 & 119 \\
\hline 4 & $\begin{array}{r}3.47 \\
S E=.13\end{array}$ & 3 & 94 \\
\hline 5 & $\begin{array}{r}4.07 \\
S E=.14\end{array}$ & 4 & 57 \\
\hline
\end{tabular}

The online version of the original article can be found under doi:10.1007/s10257-010-0131-7.

M. Marrone $(\bowtie) \cdot$ L. M. Kolbe

University of Göttingen, Platz der Göttingen Sieben 5, 37073 Göttingen, Germany

e-mail: mmarron@uni-goettingen.de

L. M. Kolbe

e-mail: 1kolbe@uni-goettingen.de 


\begin{tabular}{|c|c|}
\hline 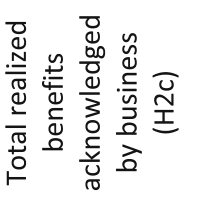 & 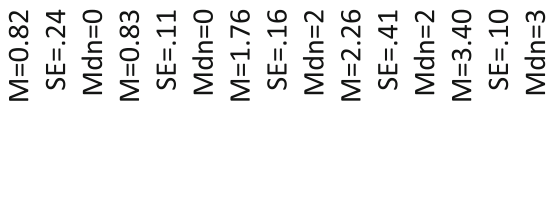 \\
\hline 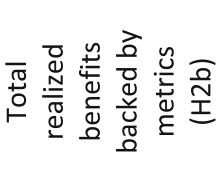 & 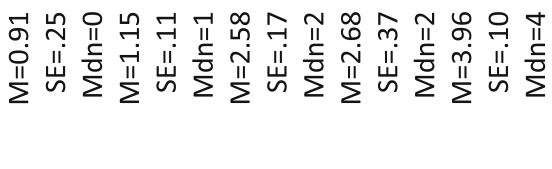 \\
\hline 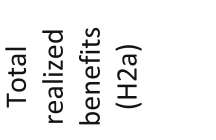 & 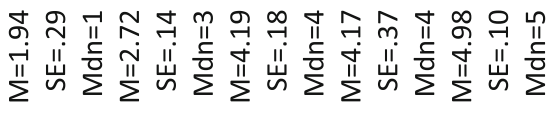 \\
\hline$z$ & 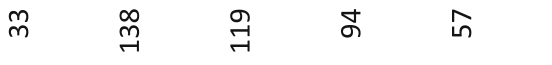 \\
\hline 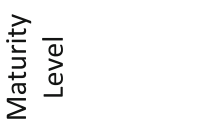 & $r \quad n \quad m$ \\
\hline
\end{tabular}

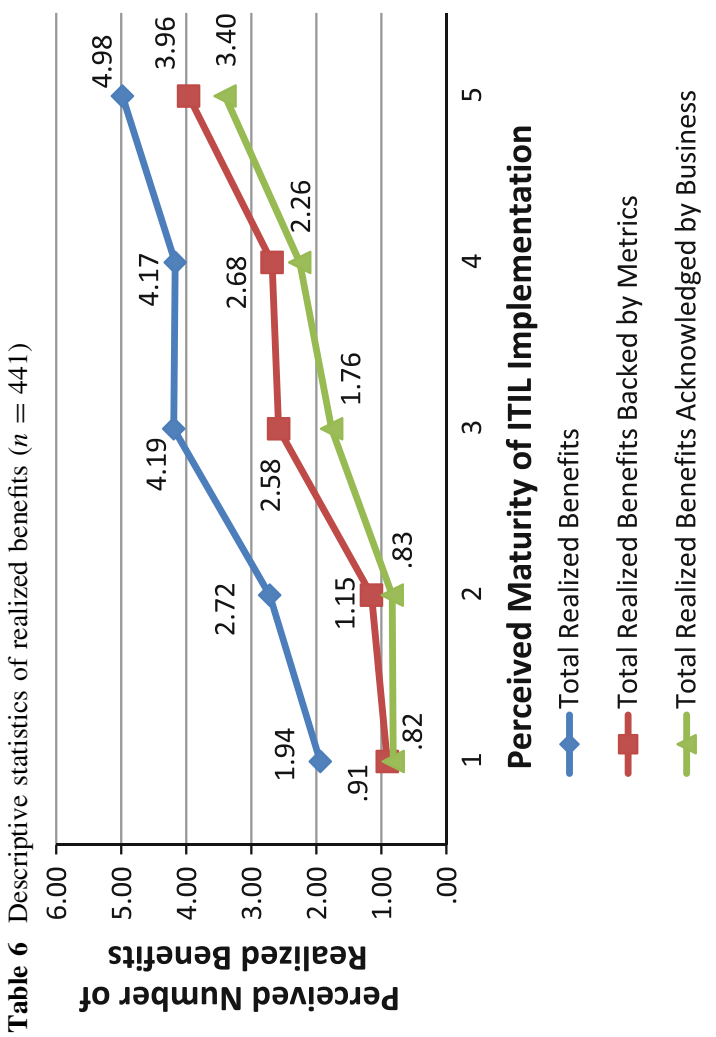

\section{型 Springer}

